\title{
Vati, da musst du durch!
}

\section{Ungehaltene After-Dinner-Speech an den Ehrengast beim Frauen-Dinner Corporate Governance, Dr. Gerhard Cromme}

173 hochkarätige Frauen aus Wirtschaft und Wissenschaft waren zum Frauendinner Corporate Governance eigens nach Berlin angereist. Sie wollten damit ihre Unterstützung für das vom djb angestoßene Projekt „Mehr Frauen in deutsche Aufsichtsräte“ signalisieren, sich untereinander austauschen und nicht zuletzt auch Sie, den deutschen „Mister Corporate Governance“, einmal kennen lernen. Denn in die Regierungskommission Deutscher Corporate Governance Kodex, welcher Sie vorsitzen, hat es ja bisher keine Frau geschafft. Insofern ein sehr gelungenes Projekt: wir Frauen haben uns gegenseitig, aber auch Sie - den für die weitere Entwicklung der deutschen Unternehmen maßgeblichen Mann - kennengelernt. So ist er eben, seufzte anschließend eine Insiderin, die Sie offenbar schon häufiger erleben durfte. Sollen auch wir anderen uns damit abfinden?

Über Ihre längere Klage bezüglich der Mühen jeder Dinner-Speech vergaßen Sie leider, sich für unsere freundliche und mit vielen Mühen verbundene Einladung zu bedanken. Nicht das Beeindrucktsein von der Präsenz und auch dem Charme so vieler Frauen, wie ich hier ausdrücklich hinzufügen möchte, war das Leitthema Ihrer Rede - was manche von uns gehofft hatten -, sondern das „Vati, da musst du durch“ Ihrer Töchter, welche Sie vorbereitend um Rat und Beistand gebeten hatten. Und wir mussten da mit Ihnen durch: Sie seien froh, dass die ebenfalls anwesende Justizministerin keine Frauenquoten für Aufsichtsräte befürworte. In deutsche Aufsichtsräte würde nur nach Qualifikation berufen und die Boards müssten sowieso eher verkleinert statt noch um Frauen angereichert werden. Frauen hätten sich eben leider zwischen Aufsichtsrat und Familie zu entscheiden mit dem bekannten Ergebnis, ließen Sie die anwesenden Frauen wissen, denen langsam nicht nur der Magen knurrte ...

Ja, wo leben Wirtschaftsführer wie Sie denn? Ich fühlte mich an die Reden meines inzwischen verstorbenen Vaters vor fünfunddreißig (!) Jahren am heimischen Mittagstisch erinnert, der mir aber immerhin klaglos ein Jurastudium finanzierte, weil er zumindest begriffen hatte, dass ich mich im Zweifel nicht für die Familie entscheiden würde...
Die Spitzenmänner der deutschen Wirtschaft seien da inzwischen doch etwas weiter, hatte nicht nur ich gehofft. Und so viel Zeit kann ein einzelnes Aufsichtsratsmandat doch gar nicht beanspruchen, wenn man die Vielzahl der Mandate bedenkt, die Männer wie Sie parallel wahrnehmen können? Zeit braucht wohl doch eher die Pflege der Beziehungen und Netzwerke, als deren Ergebnis Mann dann in Aufsichtsräte berufen wird. Und hier haben die Frauen ein Defizit, gewiss. Gerade deswegen hat der djb dieses Frauen-Dinner veranstaltet. Die Liste mit den Namen von 418 Frauen, die geeignet und bereit sind, in Aufsichtsräte zu gehen, zeigt, dass es die qualifizierten Frauen inzwischen gibt. Warum nur versuchten Sie diesen Schatz, der Ihnen auf dem Dinner nicht ohne Hintergedanken vom djb überreicht wurde, gleich an die Justizministerin weiterzureichen?

Schade, dass Sie keine Zeit fanden, sich die äußerst informativen Vorträge vor dem eigentlichen Dinner anzuhören. Professorin Osterloh hätte Ihnen erklärt, dass Unternehmen mit Frauen im Aufsichtsrat wirtschaftlich sogar besonders erfolgreich sind. Es kostet die Wirtschaft nichts, Frauen in Aufsichtsräte zu berufen, sondern bringt ihr nachweislich etwas, nicht nur moralisch oder demokratietheoretisch, auch ökonomisch. Good Corporate Governance braucht Diversity. Gut für die deutsche Wirtschaft, dass zumindest die Arbeitnehmerseite inzwischen gesetzlich verpflichtet worden ist, mehr Frauen in Aufsichtsräte zu entsenden. Künftig sollte es nun auch Frauenquoten für die Aktionärsseite geben, finde ich - gerade

Beim gesetzten Essen sprach neben der Präsidentin des djb auch die Bundesministerin der Justiz, Brigitte Zypries. Beide überreichten dem sichtlich überraschten Ehrengast Dr. Cromme eine Liste mit 418 Namen von Frauen, die befähigt und bereit sind, Aufsichtsratsmandate in deutschen Unternehmen wahrzunehmen. Damit dürfte die Behauptung, es gebe keine qualifizierten Kandidatinnen, eindrucksvoll entkräftet worden sein. Der djb freut sich deshalb auf ein baldiges Tätigwerden der Regierungskommission Deutscher Corporate Governance Kodex, wenn auch die Tischrede des Ehrengastes auf wenig diesbezügliche Tatkraft schließen ließ. 
nach Ihrer Dinner-Speech. Der djb ist da durchaus lernfähig und wird nicht lockerlassen.

In Norwegen funktionieren die Frauenquoten für Aufsichtsräte hervorragend, wie Frau Slungard vor dem Dinner zu berichten wusste, die selbst im Aufsichtsrat der Statoil ASA sitzt. 35 Prozent habe der Frauenanteil in den meisten norwegischen Aufsichtsräten bereits im Sommer 2007 betragen und die gesetzlich geforderten vollen 40 Prozent würden zum Jahresbeginn 2008 auch noch erreicht. Das dortige Gesetz hat nämlich Sanktionen: Im Extremfall könnte ein Unternehmen, das die 40-Prozent-Quote nicht erfüllt, ohne dafür gute Grunde vorbringen zu können, ab 2008 sogar aufgelöst werden!

Aber man sollte Ehrengäste nicht nur kritisieren, auch wenn ihre Tischrede enttäuschend war, sondern versöhnlich enden. Es war ein für das djbProjekt „Mehr Frauen in deutsche Aufsichtsräte“ wichtiger Beitrag, dass Sie unserer Einladung zum Frauen-Dinner gefolgt sind. Auch haben Sie, lieber
Herr Dr. Cromme, uns Frauen inzwischen damit überrascht, dass Sie für die Kapitalseite des Siemens-Aufsichtsrats im Dezember neben vier Männern mit Frau Nicola Leibinger-Kammüller auch eine erste Frau vorgeschlagen haben. Ein Anfang, auf den wir Frauen schon bei Ihrer Dinner-Speech gehofft hatten, Gratulation!

Aber bei diesem Anfang darf nicht stehengeblieben werden. Der Deutsche Corporate Governance Kodex müsste künftig als Vorgabe für gute Unternehmensführung auch eine angemessene Frauenrepräsentanz in den Aufsichtsräten verlangen. Diese Forderung teilen nach meinem Eindruck von der Reaktion auf Ihre Dinner-Speech wohl alle damaligen Teilnehmerinnen. Und darüber hinaus, wiederhole ich, sollte es künftig in Deutschland ähnlich wie in Norwegen eine Frauenquote auch für die Kapitalseite der Aufsichtsräte geben. Der djb kann nicht andauernd weitere Frauen-Dinner mit männlichen Ehrengästen veranstalten. Vati, da musst du durch!

\section{Die Auswirkungen des Bundeselterngeld- und Elternzeitgesetzes auf väterfreundliche Personalpolitik}

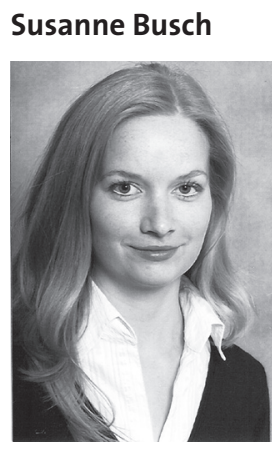

Susanne Busch Referentin im Bundesministerium für Verkehr, Bau- und Stadtentwicklung
Das Bundeselterngeld- und Elternzeitgesetz (BEEG), das am 1. Januar 2007 in Kraft getreten ist, richtet sich mit den sogenannten „Partnermonaten“ und der höheren Finanzierung speziell an Männer. Orientiert am schwedischen Modell wird das Elterngeld erstmalig einkommensabhängig für zwölf Monate ausgezahlt. Zwei weitere Monate werden dann finanziert, wenn Eltern die Betreuung des Kindes zumindest in dieser Länge partnerschaftlich teilen. Damit strebt der Gesetzgeber eine bessere Balance von Beruf und Familie für beide Geschlechter an. Doch die Vereinbarkeitswünsche von Vätern scheitern oftmals noch an der betrieblichen Realität, wie eine aktuelle Unternehmensstudie der Verfasserin zeigt. $^{1}$

Untersucht wurde ein großes Unternehmen der Ver- und Entsorgungsbranche. Mit einem Frauenanteil von 25 Prozent und in Führungsposition von lediglich von 0,16 Prozent lässt sich das Unternehmen als typische Männerdomäne einstufen. Zwischen Juli 2005 und Juli 2007 gingen im Unterneh- men insgesamt 36 Personen in Elternzeit, darunter drei Männer (8,4 Prozent), also ebenfalls dem derzeitigen Bundesdurchschnitt von 8,5 Prozent entsprechend. ${ }^{2}$ Sechs Personen wurden während ihrer Elternzeit als Teilzeitkräfte beschäftigt, darunter zwei der drei Männer. Die Männer sind im Unternehmen also stärker als die Frauen daran interessiert, während der Elternzeit nicht völlig den Kontakt zum Unternehmen zu verlieren und dadurch zu signalisieren, dass sie dem Unternehmen weiterhin zur Verfügung stehen. Ein Versuch, einem möglichen „Karriereknick“ entgegenzuwirken?

Interviews mit PersonalentscheiderInnen, der betrieblichen Sozialberatung und Betriebsratsmitgliedern, eine Gruppendiskussion mit den Vätern sowie Workshops mit Beschäftigten und Betriebsräten des Unternehmens zeigten, dass Vereinbarkeit von Beruf und Familie weder von der Unternehmensleitung noch vom Betriebsrat aktiv propagiert wird, schon gar nicht bezogen auf Männer. Nicht das neue BEEG, sondern ein langjähriger Umstrukturierungs- 